\title{
Burden of diseases in fifty-three urban agglomerations of India due to particulate matter $\left(\mathbf{P M}_{2.5}\right)$ exposure
}

\author{
Pritanjali Shende ${ }^{1^{\dagger}}$, Asif Qureshi ${ }^{1,2}$ \\ ${ }^{1}$ Department of Civil Engineering, Indian Institute of Technology Hyderabad, Kandi, Sangareddy, TS 502285, India \\ ${ }^{2}$ Department of Climate Change, Indian Institute of Technology Hyderabad, Kandi, Sangareddy, TS 502285, India
}

\begin{abstract}
A nested 3d-chemical transport model, GEOS-Chem, was used to estimate the burden of disease (BoD) from $\mathrm{PM}_{2.5}$ exposure in fifty-three urban agglomerations (UAs) in India with population of 1 million or more, and the contribution of different chemical components to the PM $\mathrm{M}_{2.5}$ burden in these locations. Premature mortality due to four diseases (ischemic heart disease, IHD, chronic obstructive pulmonary disease, COPD, stroke and lung cancer) caused by exposure to $\mathrm{PM}_{2.5}$ was estimated using an integrated exposure response function. The studied 53 UAs accounted for approximately $20 \%$ of the total premature mortality of $0.54(0.45-0.63)$ million in India. Delhi had the maximum premature mortality (11945) followed by Kolkata (9204), Mumbai (8817), Bangalore (4528) Hyderabad (4157) and Chennai (3818). Premature mortality was 2\% to 59\% higher than the country average in model regions containing UAs. Contribution from different chemical components was in the order: organic carbon $(18-30 \%)>\mathrm{NO}_{3}^{-}(8-21 \%)>\mathrm{SO}_{4}{ }^{2-}(5-16 \%)>\mathrm{NH}_{4}{ }^{+}(6-9 \%)>$ black carbon $(2.5-4 \%)$. Our estimates suggest policies targeting multiple compounds are required to achieve large reductions in $\mathrm{PM}_{2.5}$ pollution in urban regions.
\end{abstract}

Keywords: GEOS-Chem model, India, $\mathrm{PM}_{2.5}$ exposure, Premature mortality, Urban agglomeration

\section{Introduction}

Fine particulate matter with aerodynamic diameter less than 2.5 $\mu \mathrm{m}\left(\mathrm{PM}_{2.5}\right)$ is a combination of sulfate $\left(\mathrm{SO}_{4}{ }^{2-}\right)$, nitrate $\left(\mathrm{NO}_{3}{ }^{-}\right)$, ammonium $\left(\mathrm{NH}_{4}{ }^{+}\right)$, black carbon (BC), organic carbon (OC), mineral dust, sea salt aerosols and secondary organic aerosols (SOAs) [1]. It is one of the most important air-borne pollutant, causing adverse cardiovascular, cerebrovascular and respiratory effects. $\mathrm{PM}_{2.5}$ is a major cause of yearly premature mortality worldwide [2]. Sources of particulate matter include volcanoes, dust resuspension, sea-spray, forest fires, biomass burning, mechanical and industrial processes and fossil fuel burning [2]

Urban air pollution from $\mathrm{PM}_{2.5}$ is a major environmental risk to public health [3]. India had fifty-three urban agglomerations (UAs) with a population of 1 million or more in the year 2011 [4]. About $30 \%$ of the India population ( $\sim 377$ million) was reported to reside in urban areas. Several projections have been made to assess the extent of premature mortality in the entire country [5-7], but seldom specifically for urban cities. For example, results from Coupled Model Inter-comparison Project 5 (CMIP5) models have been used to project country-wide premature mortality until the year 2100 under two future representative concentration pathway (RCP) emissions scenarios RCP4.5 and RCP8.5, and five shared socioeconomic pathways (SSPs) for population [5]. In another study, the country was divided into six broad regions and the estimated premature mortality from exposure to $\mathrm{PM}_{2.5}$ in 2012 was estimated to be approximately 1.1 million [6]. The proportion of the premature mortality occurring in UAs has not been evaluated, although the UAs are well accepted to be proportionally more polluted than other regions.

A majority of studies on understanding air pollution in individual cities have focused on the national capital, New Delhi [e.g., [5, 8, 9]]. Other cities have not received as much attention even though they would account for a profound majority of urban population. In a recent study, field-observed $\mathrm{PM}_{10}$ data were used with a scaling factor to estimate $\mathrm{PM}_{2.5}$ for twenty-nine cities and it was concluded that the most important cause for premature mortality was ischemic heart disease, followed by stroke, chronic obstructive pulmonary disease, lower respiratory infection and lung cancer [10]. However, contribution of different
This is an Open Access article distributed under the terms of the Creative Commons Attribution Non-Commercial License (http://creativecommons.org/licenses/by-nc/3.0/) which permits unrestricted non-commercial use, distribution, and reproduction in any medium, provided the original work is properly cited.

Copyright (C) 2022 Korean Society of Environmental Engineers
Received January 20, 2021 Accepted April 26, 2021

${ }^{\dagger}$ Corresponding author

E-mail: ce16resch11001@iith.ac.in

Tel: +91 9309837045

ORCID: 0000-0002-5866-5561 
chemical components to $\mathrm{PM}_{2.5}$ and premature mortality was not assessed.

In this work, we used a nested chemical transport model (GEOS-Chem) to determine the premature mortality [by ischemic heart disease (IHD), chronic obstructive pulmonary disease (COPD), stroke and lung cancer (LC)] due to $\mathrm{PM}_{2.5}$ exposure in 53 UAs of India for the year 2010. We then estimated the contribution of different chemical components of $\mathrm{PM}_{2.5}\left(\mathrm{SO}_{4}{ }^{2-}\right.$, $\mathrm{NO}_{3}^{-}, \mathrm{NH}_{4}{ }^{+}, \mathrm{BC}$ and OC) to the monthly, seasonal and annual $\mathrm{PM}_{2.5}$ concentrations in each UA. The impact of these 5 chemical components of $\mathrm{PM}_{2.5}$ on the premature mortalities in $53 \mathrm{UA}$ of India was also performed. Quantification of the contribution of different components may help in prioritizing city-specific, activity-specific, emission control technologies within any broad emission category (e.g., power plants or vehicular transportation).

\section{Materials and Methods}

\subsection{Model Description and Setup}

GEOS-Chem is a 3-dimensional atmospheric chemical transport model (http://acmg.seas.harvard.edu/geos/) driven by assimilated meteorological data from the Goddard Earth Observing System (GEOS). We simulated $\mathrm{PM}_{2.5}$ concentrations over India using the $0.5^{\circ} \times 0.625^{\circ}$ Asian nested grid in GEOS-Chem version v12.1.1 $\left(11^{\circ} \mathrm{S}-55^{\circ} \mathrm{N}, 60^{\circ} \mathrm{E}-150^{\circ} \mathrm{E}\right)$ for the year 2010 , which uses MERRA2 meteorological data. Boundary conditions for the nested simulation were generated every $3 \mathrm{~h}$ from the global $4^{\circ} \times 5^{\circ}$ version of the model [11]. Fully coupled simulations included $\mathrm{O}_{3}$-NOx-hydrocarbon chemistry, aerosols and gas-aerosol phase partitioning, and dry and wet deposition schemes [12-18].

Global anthropogenic emissions were from the Community Emissions Data System (CEDS) except for $\mathrm{NH}_{3}$ emissions, which were from the Global Emission Initiative (GEIA) inventory [19]. Anthropogenic emissions over the Asian region (nested grid) were from MIX inventory [20]. The MIX emission inventory for 2010 considers ten species $\left[\mathrm{SO}_{2}, \mathrm{NOx}, \mathrm{NH}_{3}, \mathrm{CO}\right.$, non-methane volatile organic carbon (NMVOC), $\mathrm{PM}_{10}, \mathrm{PM}_{2.5}$, BC, OC and $\mathrm{CO}_{2}$ ] from five different sectors (residential, industry, power, transport and agriculture) [20]. Total anthropogenic and natural emissions over the Indian region are presented in the Supplementary Material (Table S1 and Fig. S1). Each simulation was made for 18 months, with the first 6 months as spin-up for both global $\left(4^{\circ} \times 5^{\circ}\right)$ and the nested $\left(0.5^{\circ} \times 0.625^{\circ}\right)$ models [21].

Model outputs were saved at monthly resolution and included total $\mathrm{PM}_{2.5}$ concentrations in each model grid, and the concentrations of different components of $\mathrm{PM}_{2.5}\left(\mathrm{SO}_{4}{ }^{2-}, \mathrm{NO}_{3}{ }^{-}, \mathrm{NH}_{4}{ }^{+}, \mathrm{BC}, \mathrm{OC}, \mathrm{SOA}\right.$, mineral dust and sea salt aerosols). From this, the percent contributions by chemical components $\left(\mathrm{SO}_{4}{ }^{2-}, \mathrm{NO}_{3}{ }^{-}, \mathrm{NH}_{4}{ }^{+}, \mathrm{BC}\right.$ and $\mathrm{OC}$ ) to $\mathrm{PM}_{2.5}$ concentrations were estimated because understanding the variation in the concentration of different components and their relationship with the emissions, helps in generating policies for the future [1]. The premature mortalities in each model region containing UAs were also calculated.
A population-weighted annual mean $\mathrm{PM}_{2.5}$ concentration for the entire country was calculated as:

$$
\text { Population - weighted } P M_{2.5}=\frac{\sum_{i=1}^{N} P M_{2.5} \times P_{i}}{\sum_{i=1}^{N} P_{i}}
$$

Population-weighted concentration (for individual grid $i$ ranging from 1 to $N$ ) is the mean concentration to which the entire country population $(P)$ may be exposed to $\mathrm{PM}_{2.5}\left(\mu \mathrm{g} \mathrm{m}^{-3}\right)$ [22] and accounts for the variation in spatial and temporal distribution of $\mathrm{PM}_{2.5}$ [23].

\subsection{Observational and Satellite Data for Comparison}

We compared GEOS-Chem simulated $\mathrm{PM}_{2.5}, \mathrm{SO}_{2}$ and $\mathrm{NO}_{2}$ concentrations with observed annual mean concentrations of PM.2.5 (at eleven sites, Table S2), $\mathrm{SO}_{2}$ and $\mathrm{NO}_{2}$ (at 48 UAs) in 2010 by the National Ambient Air Quality Monitoring Programme, NAMP [24]. Details on locations and observed concentrations of $\mathrm{SO}_{2}$ and $\mathrm{NO}_{2}$ are presented in the Supplementary Material (Table S3 and S4). As ground-based observations for $\mathrm{PM}_{2.5}$ were scarce, re-gridded satellite derived concentrations obtained from the aerosol optical depth (AOD) values retrieved from Moderate Resolution Imaging Spectroradiometer (MODIS), Multi-angle Imaging Spectroradiometer (MISR) and Sea-Viewing Wide Field-of-View Sensor (SeaWiFS) [25] were also used. Normalized mean bias (NMB) (Eq. (2)) and coefficients of correlation (r) of model (M) predicted $\mathrm{PM}_{2.5}, \mathrm{SO}_{2}$ and $\mathrm{NO}_{2}$ concentrations with the corresponding ground-based or satellite-based observations (O) were determined.

$$
N M B=100 \times \frac{\sum_{1}^{n}(M-O)}{\sum_{1}^{n}(O)}
$$

\subsection{Estimation of Premature Mortality due to $\mathrm{PM}_{2.5}$ Exposure and Contribution of Chemical Components to $\mathrm{PM}_{2.5}$}

Four diseases IHD, COPD, stroke and LC were used as endpoints because of their direct link with ambient $\mathrm{PM}_{2.5}$ exposure [26-28]. Relative risks of these diseases were calculated for each model grid using a non-linear Integrated Exposure Response (IER) function $[5,29-31]$ :

$$
\begin{gathered}
R R_{i, j}=1+\alpha_{j}\left[1-\exp \left(-\gamma_{j}\left(\Delta P M_{2.5}\right)_{i}^{\delta_{j}}\right)\right. \\
R R_{i, j}=1\left(\text { If } P M_{2.5}<5.8 \mu g m^{-3}\right)
\end{gathered}
$$

Where $R R_{i, j}$ represents the relative risk for a disease $\mathrm{j}$ at a model grid i. $\triangle P M_{2.5}$ is the difference between the modeled $\mathrm{PM}_{2.5}$ concentration $\left(\mu \mathrm{g} \mathrm{m}^{-3}\right)$ in the $\mathrm{i}^{\text {th }}$ grid and the counterfactual $\mathrm{PM}_{2.5}$ concentration, $5.8 \mu \mathrm{g} \mathrm{m}^{-3}$ [31]. The counterfactual $\mathrm{PM}_{2.5}$ concentration is the amount of $\mathrm{PM}_{2.5}$ below which no risk exists (i.e. $R R \leq 1$ ) [31]. A range of 1,000 sets of disease specific constants $\left(\alpha_{j}, \gamma_{j}, \delta_{j}\right)$ were obtained from the Monte Carlo simulation performed by Burnett et al. [30]. The median and 95\% confidence limits (CLs) of these constants are presented in Table S5. Premature mortality per year, $\Delta M_{i, j}$, is given by [30, 32]: 


$$
\sum_{i, j=1}^{N} \Delta M_{i, j}=\sum_{i, j=1}^{N} y_{i, j} \times \frac{\sum_{i=1}^{N} R R_{i, j}-1}{\sum_{i=1}^{N} R R_{i, j}} \times \sum_{i=1}^{N} P_{i}
$$

Where $y_{i, j}$ is the baseline mortality (unitless), $\mathrm{RR}_{\mathrm{i}, \mathrm{j}}$ is the relative risk for specific disease $\mathrm{j}$ at modelled grid (i to $\mathrm{N}$ ) and $P_{i}$ is the exposed population for 2010. The 2010 total population information was obtained from 2011 census data [33]. The $0.5^{\circ}$ $\times 0.5^{\circ}$ gridded population for the year 2010 was obtained from the Shared Socioeconomic Pathways (SSP) scenarios (https://tntcat.iiasa.ac. at/SspD, last accessed 8 October, 2020) and regridded to the simulation resolution $\left(0.5^{\circ} \times 0.625^{\circ}\right)$. The baseline mortality was quantified using the number of deaths in India for 2010 from the Global Health Database Exchange [http://ghdx.healthdata.org, last accessed 03 July, 2020; data is provided by the Office of the Registrar General and Census Commissioner, India (2014)].

The impact of individual chemical components of $\mathrm{PM}_{2.5}$ on the premature mortality was estimated by first subtracting the individual component from the actual $\mathrm{PM}_{2.5}$ concentration in the respective UA location. Later the premature mortality by 4 different diseases (COPD, IHD, lung cancer and stroke) at these UAs of India from the obtained $\mathrm{PM}_{2.5}$ concentration was determined by using IER function. The total premature mortality due to a specific chemical constituent is estimated by deducing the premature mortality estimated in absence of the specific chemical component from the total premature mortality value.

\section{Results}

\subsection{Model Results and Country-Wide Analysis}

Overall country-wide results were similar to other previous studies. Population weighted mean concentration of $\mathrm{PM}_{2.5}$ was $66.2 \mu \mathrm{g}$ $\mathrm{m}^{-3}$, approximately 12\% lower than Ghude et al. [7], 2016 (75 $\mu \mathrm{g} \mathrm{m}^{-3}$ in 2011), David et al. [6], 2019 (75.5 $\mu \mathrm{g} \mathrm{m}^{-3}$ in 2012), Venkataraman et al. [34], $2018\left(\sim 75 \mu \mathrm{g} \mathrm{m}^{-3}\right.$ in 2015) and $10 \%$ higher than Cohen et al. [35], 2017 (60 $\mu \mathrm{g} \mathrm{m}^{-3}$ in 1990), but within the percent variation $(\sim 7-15 \%)$ reported from multiple studies [6]. 99.5\% of the total population in India was exposed to an annual mean $\mathrm{PM}_{2.5}$ concentration greater than the WHO air quality guidelines (annual mean concentration of $10 \mu \mathrm{g} \mathrm{m}^{-3}$ ); [36], similar to earlier results [6, 34, 37].

The highest mean surface concentrations of $\mathrm{PM}_{2.5}$ were observed during DJF (December-January-February) followed by SON (September-October-November), MAM (March-April-May) and JJA (June-July-August) (Fig. 1). A decrease in the concentration of $\mathrm{PM}_{2.5}$ and its precursors during JJA occurs due to precipitation and washout or wet deposition of pollutants in the atmosphere whereas a peak in the concentrations during DJF in India occurs due to low temperatures and low mixing heights [38] limiting the dispersion of pollutants.

The annual average concentrations of $\mathrm{NO}_{3}{ }^{-}, \mathrm{NH}_{4}{ }^{+}, \mathrm{SO}_{4}{ }^{2-}, \mathrm{BC}$, OC, SOA, mineral dust, and sea salt aerosols over India for the year 2010 were estimated as $6.90 \mu \mathrm{g} \mathrm{m}^{-3}, 3.92 \mu \mathrm{g} \mathrm{m} \mathrm{m}^{-3}, 5.21 \mu \mathrm{g}$

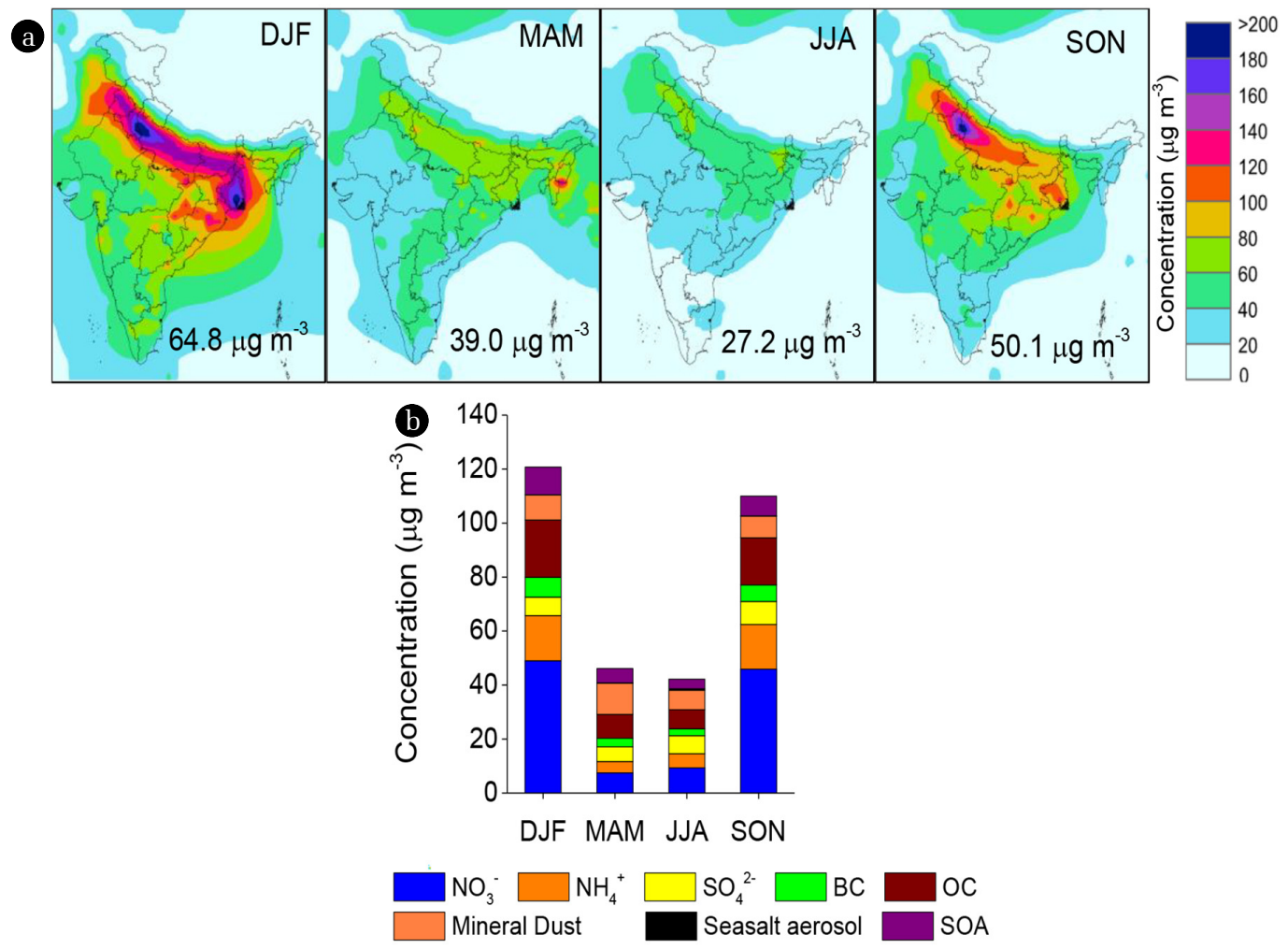

Fig. 1. (a) Spatial and seasonal variation in the concentration $\left(\mu \mathrm{g} \mathrm{m}^{-3}\right)$ of $\mathrm{PM}_{2.5}$ with the inset values as the seasonal mean concentration of $\mathrm{PM}_{2.5}$ and (b) the seasonal mean concentration of different components of $\mathrm{PM}_{2.5}$ for the year 2010 in India. 
$\mathrm{m}^{-3}, 1.7 \mu \mathrm{g} \mathrm{m}^{-3}, 5.1 \mu \mathrm{g} \mathrm{m}^{-3}, 7.2 \mu \mathrm{g} \mathrm{m}^{-3}, 10.38 \mu \mathrm{g} \mathrm{m}^{-3}$ and 0.21 $\mu \mathrm{g} \mathrm{m}^{-3}$, respectively. The percent contribution of sulfate-nitrate-ammonium (SNA) to $\mathrm{PM}_{2.5}$ over India was observed to be $40 \%$ (with $\mathrm{NO}_{3}{ }^{-}$contributing by as $16 \%, \mathrm{SO}_{4}{ }^{2-}$ by $14 \%$ and $\mathrm{NH}_{4}{ }^{+}$ by $10 \%$ to $\mathrm{PM}_{2.5}$ concentration). OC concentration contributed $21 \%$ to $\mathrm{PM}_{2.5}$ followed by mineral dust (18\%), secondary organic aerosols $(17 \%), \mathrm{BC}(3 \%)$ and sea salt aerosols (1\%). The northern Indian region (mainly the IGP region) has the highest ambient $\mathrm{PM}_{2.5}$ concentration, similar to other studies [6]. Fig. S2 and S3 present the annual spatial and monthly mean variations in the concentrations of various chemical constituents $\left(\mathrm{NO}_{3}{ }^{-}, \mathrm{NH}_{4}{ }^{+}\right.$, $\mathrm{SO}_{4}{ }^{2-}, \mathrm{BC}$ and $\mathrm{OC}$ ) of $\mathrm{PM}_{2.5}$ in India. The Indo-Gangetic plains were observed to have high concentrations of different chemical constituents of $\mathrm{PM}_{2.5}$.

Further discussions on comparison of model results with field-observed and satellite-derived concentrations and related discussions are presented in Section S1 and Fig. S4 and, on premature mortality in India as a whole in Section S2. The total premature mortality in India was $0.54(0.45-0.63)$ million (Table S6), comparable to previous reports [0.57 (0.32-0.73) million [7] and 0.567 million [39]]. Maximum premature mortality was observed in the Indo-Gangetic region (Fig. S5).

\section{2. $\mathrm{PM}_{2.5}$ and Premature Mortality in the 53 UAs of India}

The annual average concentration of $\mathrm{PM}_{2.5}$ in all the UAs were
$>10 \mu \mathrm{g} \mathrm{m}^{-3}$ (range 26.06-144.33 $\mu \mathrm{g} \mathrm{m}^{-3}$ ). Fig. 2(a) and Table S7 show the premature mortalities obtained in the UAs for 2010. The total number of premature mortality due to $\mathrm{PM}_{2.5}$ exposure in these UAs was 0.10 (0.09-0.125) million for the year 2010. Delhi had the highest mortality (11945), followed by Kolkata (9204), Mumbai (8817), Bangalore (4528) Hyderabad (4157) and Chennai (3818). Together these cities account for $7.86 \%$ of the total premature mortalities in India and $42.47 \%$ of total premature mortalities in UAs.

Fig. 2(b) and Table S8 show the premature mortality per capita, i.e. the mortality per population due to $\mathrm{PM}_{2.5}$ exposure in each UA. This number is directly related to the $\mathrm{PM}_{2.5}$ concentrations in each UA [see Eq. (3), [39]]; the higher the $\mathrm{PM}_{2.5}$ concentrations (Fig. 4) the higher will be the premature mortality per capita. The most vulnerable UAs are Delhi, Kolkata, Lucknow, Kanpur, Ghaziabad, Patna, Agra, Ludhiana, Faridabad, Meerut, Jamshedpur, Asansol, Allahabad, Amritsar and Dhanbad, with 0.065\% premature mortality per capita. All these are higher than the country average of $0.047 \%$ premature mortality per capita. That is, premature mortality due to $\mathrm{PM}_{2.5}$ exposure was $2 \%$ to $59 \%$ higher in the regions containing UAs than the country average. Across all the cities, the causes of mortalities were Stroke $\approx$ IHD $>$ COPD $>$ LC (Fig. S6).

The premature mortality with respect to population in the rural regions ranged from $0.02 \%$ to $0.069 \%$ with the average of $0.052 \%$ (Section S3, Table S9-S11, Fig. S7-S8; rural regions obtained from the Ministry of Jal Shakti, Government of India, website,
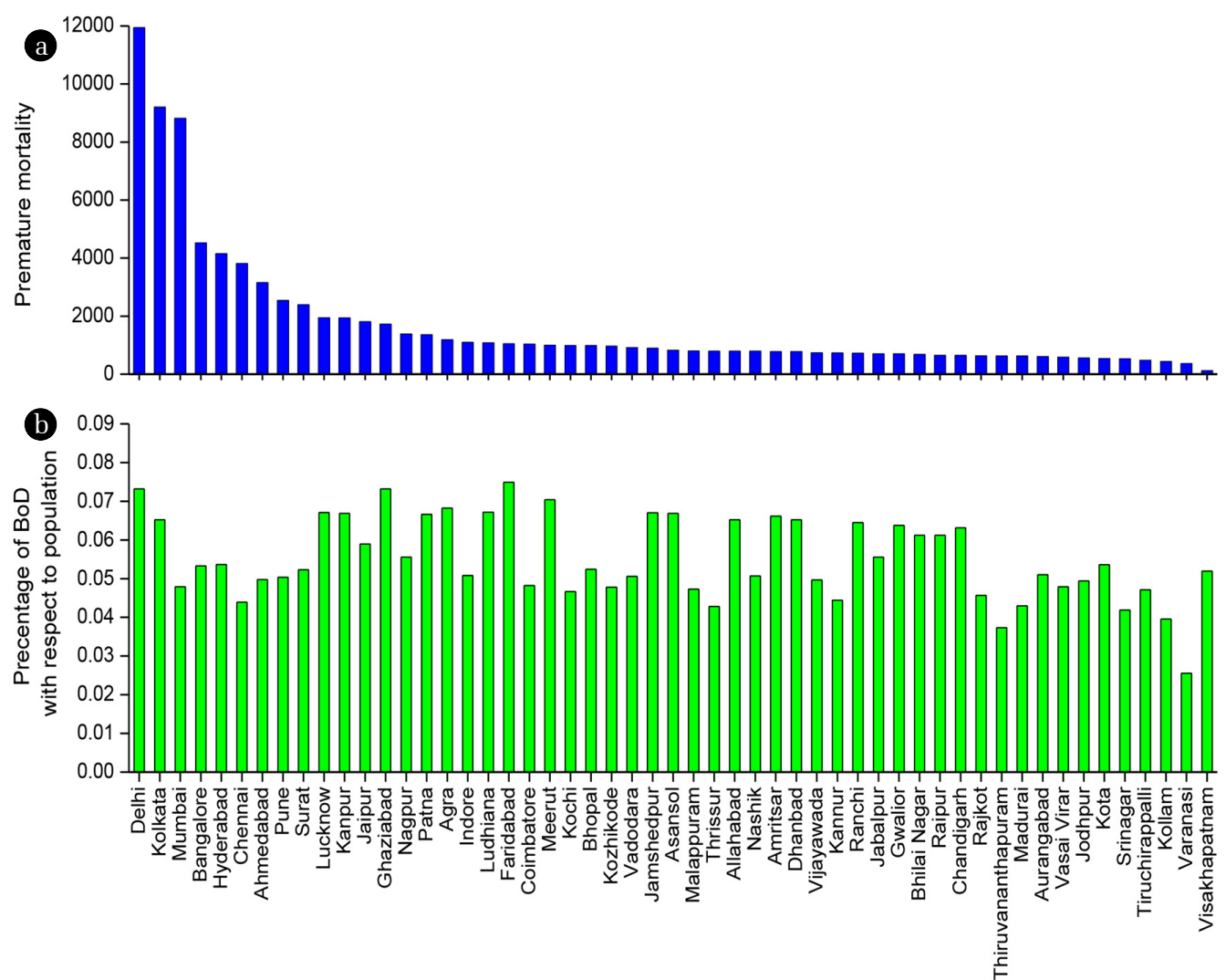

Fig. 2. (a) Premature mortality and (b) percent $B o D$ with respect to the population in 53 UAs of India. 
https://ejalshakti.gov.in/IMISReports/Reports/BasicInformation/rpt _RWS_RuralPopulation_S.aspx?Rep $=0 \& R P=Y$, last accessed 05 April, 2021; [40, 41]). The annual average $\mathrm{PM}_{2.5}$ concentrations in these rural sites was $50.1 \mu \mathrm{g} \mathrm{m}^{-3}\left(12.5 \mu \mathrm{g} \mathrm{m}^{-3}\right.$ at Pangi region of Chamba district of Himachal Pradesh to $105.33 \mu \mathrm{g} \mathrm{m}^{-3}$ at Jakhal region of Fatehabad of Haryana state). As can be seen, some values were lower than the country average of $0.047 \%$ and some were higher $(1.2-50.6 \%)$ than the country average. We then plotted the $\mathrm{PM}_{2.5}$ concentrations in UAs and rural regions by five administrative zones of India (northern, southern, eastern, western and central India as shown in Fig. S8). It is seen that $\mathrm{PM}_{2.5}$ concentrations in rural regions in southern and eastern India do not statistically differ from those in UAs (Fig. S9). Whereas, in the northern, western and central India the $\mathrm{PM}_{2.5}$ concentrations in rural regions were lower than UAs at $\mathrm{p}<0.05$. When observed together with the spatial annual mean concentrations of $\mathrm{NO}_{3}{ }^{-}, \mathrm{NH}_{4}{ }^{+}, \mathrm{SO}_{4}{ }^{2-}, \mathrm{BC}$ and OC, and the overall seasonal $\mathrm{PM}_{2.5}$ map (Fig. 1), it appears that the pollution from $\mathrm{PM}_{2.5}$ is largely zonal. That is, in most cases, the percent BoD would be similar in rural, semi-urban and urban locations that belong to one particular region, and the absolute premature mortality then essentially dependent on the absolute population residing in that region. Therefore, pollution reduction measures taken in certain high emission regions of a particular zone may be beneficial to the entire zone.

\subsection{Premature Mortality due to the Different Constituents of $\mathrm{PM}_{2.5}$}

Fig. 3 and Table S12 present the premature mortality contributed by different chemical components of $\mathrm{PM}_{2.5}$ in India for the simulated year 2010. Cities like Delhi, Kolkata, Surat, Mumbai, Hyderabad,
Chennai, Bangalore and Ahmedabad had the premature mortalities ranging from 337 to 1,136 by $\mathrm{OC}, 215$ to 996 by $\mathrm{NO}_{3}{ }^{-}, 210$ to 828 by $\mathrm{SO}_{4}^{2-}, 150$ to 625 by $\mathrm{NH}_{4}^{+}$and 51 to 567 by BC respectively. The contribution of differnet chemical components was in the order: $\mathrm{OC}>\mathrm{NO}_{3}{ }^{-}>\mathrm{SO}_{4}{ }^{2-}>\mathrm{NH}_{4}{ }^{+}>$BC. Pemature mortality due to $\mathrm{NO}_{3}{ }^{-}, \mathrm{NH}_{4}{ }^{+}$and $\mathrm{OC}$ are proportionately much higer in the Indo-Gangetic Plains (Fig. 3), which could be attributable to vehicular, agrilcutural and biomass burning emissions (e.g. [34]). Premature mortality due to $\mathrm{SO}_{4}{ }^{2-}$ coincides relatively well with the locations of coal-fired power plants (e.g., in Jharkhand, greater Delhi region, Uttar Pradesh and Maharashtra).

\subsection{Composition of $\mathrm{PM}_{2.5}$ and Implications for Remedial Actions}

Fig. 4(a) and Fig. 4(b) present the concentrations and the contribution of $\mathrm{SO}_{4}{ }^{2-}, \mathrm{NO}_{3}{ }^{-}, \mathrm{NH}_{4}{ }^{+}$, $\mathrm{BC}$ and $\mathrm{OC}$ on $\mathrm{PM}_{2.5}$ for the UAs of India for the year 2010. OC concentration contributed the most (18-30\%) to the total $\mathrm{PM}_{2.5}$ concentration, followed by $\mathrm{NO}_{3}^{-}(10-$ $28 \%), \mathrm{SO}_{4}{ }^{2-}(7-21 \%), \mathrm{NH}_{4}{ }^{+}(7-12 \%)$ and $\mathrm{BC}(2.5-4 \%)$, respectively for the different UAs. In general, strategies to reduce OC and NOx pollution may be expected to yield health benefits across all the cities. Furthermore, measures that target the residential or biomass burning [42], and transportation sector should lead to benefits in most UAs.

However, measures to reduce the impact of $\mathrm{NO}_{3}{ }^{-}$should be applied across all major categories of transportation (buses, taxis, cars, private, public). For example, cities like Delhi have implemented short-duration odd-even schemes in the past whereby all private four-wheelers with an odd registration numbers are allowed to be on-road one day and even registration numbers on

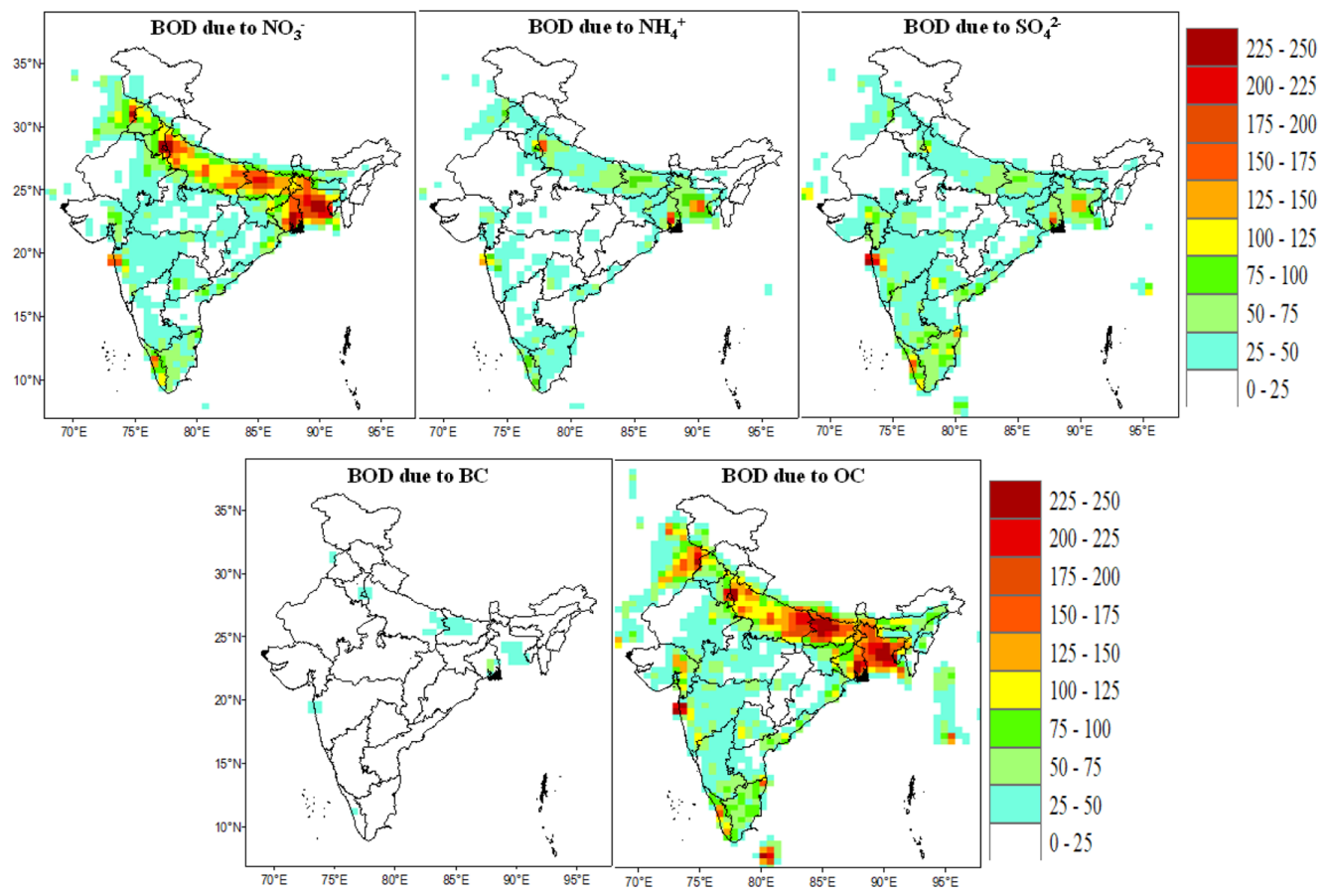

Fig. 3. The impact of different chemical components on the premature mortality due to $\mathrm{PM}_{2.5}$ in India during 2010 . 

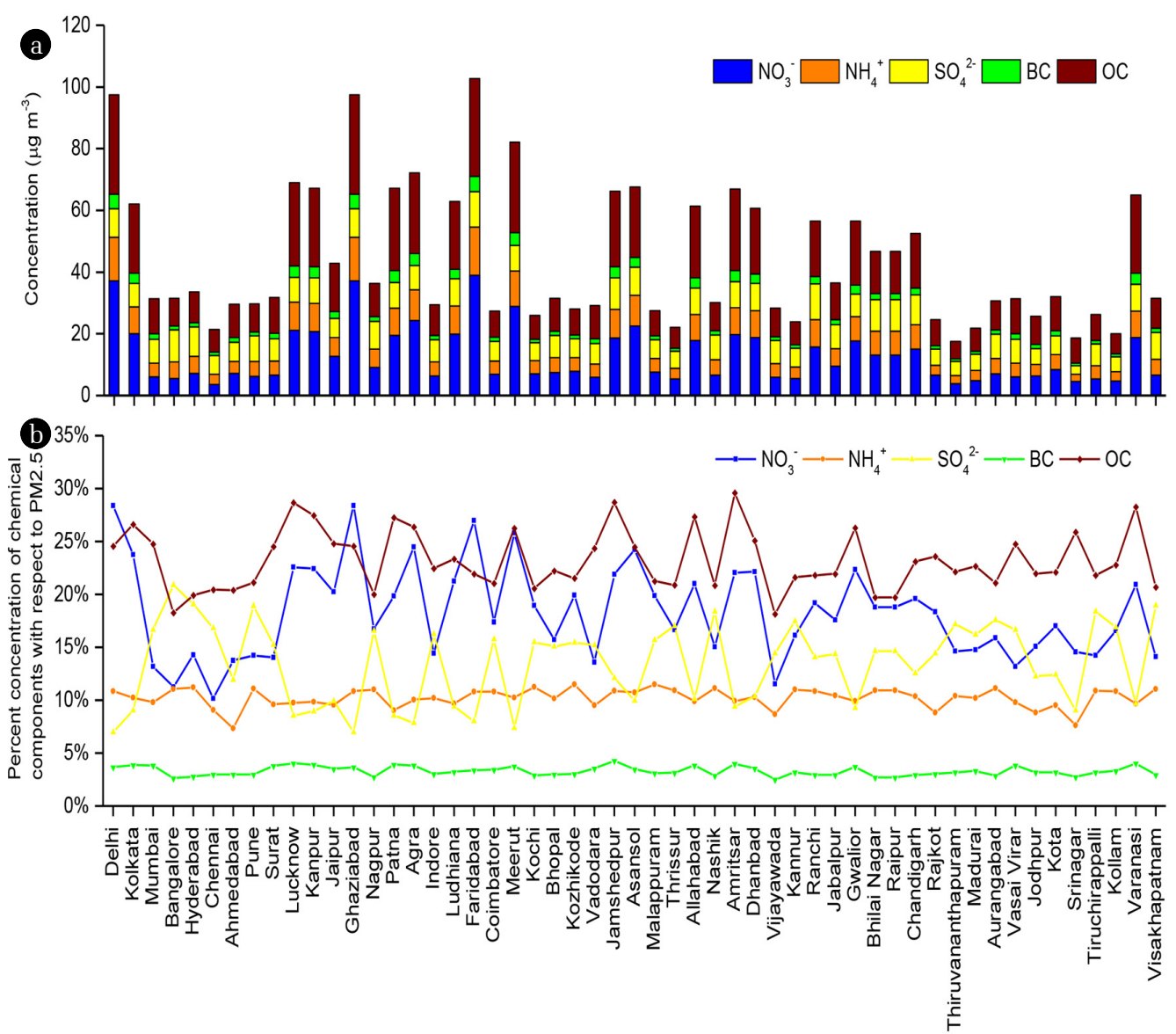

Fig. 4. (a)The annual mean concentration of the chemical components of $\mathrm{PM}_{2.5}$ and (b) the percent contribution of these chemical components to $\mathrm{PM}_{2.5}$ at the 53 UAs of India for the year 2010 .

the next day. And the most recent scheme applied between November 5 and 15, 2019, had several concessions, with restrictions being applicable only between 8 am and $8 \mathrm{pm}$, with exemptions for female drivers with children up to age 12, vehicles with physically disabled person and elderly people and on Sundays. These schemes have been applied to obtain short-term improvement in air quality and their long-term effectiveness has been judged to be marginal only [43, 44].

If we assume that such a scheme is applied consistently throughout the year, considering $48 \%$ of $\mathrm{NO}_{2}$ contribution from passenger vehicles [45] and 33\% from cars and jeep [43], an overall $\mathrm{NO}_{2}$ reduction of the order of $8 \%$ can be expected if half of the cars and jeep were removed from the roads. $\mathrm{NO}_{3}{ }^{-}$contributed approximately $16 \%$ to total $\mathrm{PM}_{2.5}$ concentrations in Delhi region in our model results and an overall 1.3\% reduction of $\mathrm{PM}_{2.5}$ concentration can be expected. Model predicted $\mathrm{PM}_{2.5}$ and $\mathrm{NO}_{2}$ concentrations for the Delhi grid will be $66.87 \mu \mathrm{g} \mathrm{m}^{-3}$ and $7.72 \mu \mathrm{g} \mathrm{m}^{-3}$, respectively, which are comparable to the measured $\mathrm{PM}_{2.5}$ and NO2 concentrations by CPCB, 79-507 $\mu \mathrm{g} \mathrm{m}^{-3}$ and 9-159 $\mu \mathrm{g} \mathrm{m}^{-3}$, respectively during the $1^{\text {st }}$ to $15^{\text {th }}$ January 2016 (http://cpcbenvis.nic.in/pdf/ CPCB\%20Report\%20on\%20Odd-Even\%20Scheme.pdf). Thus, even though our $1.3 \%$ reduction calculations are derived using assumptions, they suggest that such odd-even schemes applied to a small section of overall traffic will not lead to high reductions; instead, they may be more useful in reducing traffic congestion and travel times [43]. Further considering the natural variability in measurements, such reductions may not be observed at a statistically significant level. In contrast, switching to tighter emissions norms [such as under the Bharat Stage (BS)-VI], introduced on $1^{\text {st }}$ April 2020, will reduce NOx emissions from petrol-driven vehicles by $25 \%$ and from diesel-driven vehicles by $68 \%$. Therefore, here, more than $10 \%$ reduction in $\mathrm{PM}_{2.5}$ can be expected due to local NOx emissions reductions alone.

$\mathrm{SO}_{2}$ emissions are largely driven by the industrial and power sectors, and their contribution to urban $\mathrm{PM}_{2.5}$ load is variable (10$30 \%$ ). However, technologies such as flue gas desulfurization (FGD) installed in all coal-fired power plants [46] can remove as much as $90 \%$ of this contribution.

Contributions of $\mathrm{NH}_{4}{ }^{+}$, BC and OC to $\mathrm{PM}_{2.5}$ are consistent across all analyzed UAs (total 35-50\%) and are primarily influenced by the residential sector (like emissions from traditional stove, biofuels, cow dung and agricultural waste used for cooking). This is consistent with previous country-wide model results that the residential sector could account for $52 \%$ of population-weighted annual mean $\mathrm{PM}_{2.5}$ concentrations [37]. The percent premature mortality is much higher in urban areas (2-59\%) than the country-wide estimate. Therefore, 
a move away from low efficiency combustion of domestic fuels [47], limiting biomass burning during winters and alternative power sources such as diesel generators would substantially reduce $\mathrm{PM}_{2.5}$ pollution, and the associated exposure and premature mortality in urban regions as well as the entire country.

As such, our analysis shows policies targeting multiple sectors would lead to larger reductions in $\mathrm{PM}_{2.5}$ pollution in urban regions (reductions of more than 19-30\%) compared to policies in a single sector alone. Overall, a multi-pronged approach will be required to improve the overall air quality of urban regions.

\section{Conclusions}

The premature mortality from $\mathrm{PM}_{2.5}$ exposure was estimated to be 0.54 million for India in 2010 and 0.1 (0.09-0.125) million for the 53 considered UAs. Delhi had the highest premature mortality followed by Kolkata, Mumbai, Bangalore, Hyderabad and Chennai, accounting for $7.5 \%$ of the total premature mortalities in India and $47.6 \%$ of the total premature mortalities of all the UAs from $\mathrm{PM}_{2.5}$ exposure. The cause of mortality in the UAs was Stroke $\approx \mathrm{IHD}>\mathrm{COPD}>\mathrm{LC}$. The health effects of the chemical components of $\mathrm{PM}_{2.5}$ showed a trend of OC having higher contribution towards the total premature mortality in India followed by $\mathrm{NO}_{3}^{-}, \mathrm{SO}_{4}^{2-}$, $\mathrm{NH}_{4}{ }^{+}$and BC respectively. Multiple source-specific remedial measures such as implementation of new vehicular emission norms (for example, BS-VI standards), installation of FGDs in power plants and robust actions to control the emissions from the unregulated sources (residential and biomass burning) near urban regions could lead to a reduction of $19-30 \%$ of the $\mathrm{PM}_{2.5}$ concentrations in these regions.

\section{Acknowledgments}

The MERRA-2 data used in this study/project have been provided by the Global Modeling and Assimilation Office (GMAO) at NASA Goddard Space Flight Center. Contents and views expressed in this manuscript are of the authors alone and do not necessarily reflect the views of IIT Hyderabad.

\section{Author Contributions}

A.Q. (Associate Professor) initiated the study, wrote and edited the manuscript. P.S. (Ph.D. Scholar) conceptualized the plan, performed simulations, visualized the data, wrote and edited the manuscript.

\section{References}

1. Geng G, Zhang Q, Tong D, et al. Chemical Composition of Ambient PM2. 5 over China and Relationship to Precursor Emissions during 2005-2012. Atmos. Chem. Phys. 2017;17:91879203.
2. Anderson JO, Thundiyil JG, Stolbach A. Clearing the Air: A Review of the Effects of Particulate Matter Air Pollution on Human Health. J. Med. Toxicol. 2012;8:166-175.

3. WHO. Assessing the Environmental Burden of Disease at National and Local Levels. World Health Organization Protection of Human Environment Geneva. 2003.

4. India Medical Certification of Cause of Death (MCCD). GHDx [cited on 8 January 2021]. Available from: http://ghdx.healthdata.org/series/india-medical-certification-cause-death-mccd.

5. Chowdhury S, Dey S, Smith KR. Ambient $\mathrm{PM}_{2.5}$ Exposure and Expected Premature Mortality to 2100 in India under Climate Change Scenarios. Nat. Commun. 2018;9:318.

6. David LM, Ravishankara AR, Kodros JK, Pierce JR, Venkataraman C, Sadavarte P. Premature Mortality Due to PM 2.5 Over India: Effect of Atmospheric Transport and Anthropogenic Emissions. GeoHealth. 2019;3:2-10.

7. Ghude SD, Chate DM, Jena C, et al. Premature Mortality in India Due to $\mathrm{PM}_{2.5}$ and Ozone Exposure. Geophys Res. Lett. 2016;43:1-10.

8. Bikkina S, Andersson A, Kirillova E, et al. Air Quality in Megacity Delhi Affected by Countryside Biomass Burning. Nat. Sustain. 2019;2:200-205.

9. Sawlani R, Agnihotri R, Sharma C. Chemical and Isotopic Characteristics of $\mathrm{PM}_{2.5}$ over New Delhi from September 2014 to May 2015: Evidences for Synergy between Air-Pollution and Meteorological Changes. Sci. Total Environ. 2020;763:142966.

10. Saini P, Sharma M. Cause and Age-Specific Premature Mortality Attributable to $\mathrm{PM}_{2.5}$ Exposure: An Analysis for Million-Plus Indian Cities. Sci. Total Environ. 2020;710:135230.

11. Zhang L, Zhao T, Gong S, et al. Updated Emission Inventories of Power Plants in Simulating Air Quality during Haze Periods over East China. Atmos. Chem. Phys. 2018;18:2065-2079.

12. Alexander B, Park RJ, Jacob DJ, et al. Sulfate Formation in Sea-Salt Aerosols: Constraints from Oxygen Isotopes. J. Geophys. Res. 2005;110.

13. Fairlie TD, Jacob DJ, Park RJ. The Impact of Transpacific Transport of Mineral Dust in the United States. J. Atmos. Envi. 2007;41:1251-1266

14. Fountoukis C, Nenes A. ISORROPIA II: A Computationally Efficient Thermodynamic Equilibrium Model for $\mathrm{K}^{+}-\mathrm{Ca}^{2+}$. $\mathrm{Mg}^{2+}-\mathrm{NH}^{4+}-\mathrm{Na}^{+}-\mathrm{SO}_{4}{ }^{2-}-\mathrm{NO}_{3}{ }^{-}-\mathrm{Cl}^{-}-\mathrm{H}_{2} \mathrm{O}$ Aerosols. Atmos. Chem. Phys. 2007;7:1893-1939.

15. Mari C, Jacob D, Bechtold P. Transport and Scavenging of Soluble Gases in a Deep Convective Cloud. J. Geophys. Res. 2000;105: 22255-22268.

16. Park RJ, Jacob DJ, Chin M, Martin RV. Sources of Carbonaceous Aerosols over the United States and Implications for Natural Visibility. J. Geophys. Res. 2003;108:1-19.

17. Pye HOT, Liao H, Wu S, et al. Effect of Changes in Climate and Emissions on Future Sulfate-Nitrate-Ammonium Aerosol Levels in the United States. J. Geophys. Res. 2009;114:1-18.

18. Wesely ML. Parameterization of Surface Resistances to Gaseous Dry Deposition in Regional-Scale Numerical Models. Atmos. Environ. 2007;41:52-63.

19. Bouwman AF, Lee DS, Asman WAH, Dentener FJ, Hoek KWVD, Olivier JGJ. A Global High-Resolution Emission Inventory for Ammonia. Global Biogeochem. Cycles. 1997;11:561-587. 
20. Li M, Zhang Q, Kurokawa JI, et al. MIX: A Mosaic Asian Anthropogenic Emission Inventory under the International Collaboration Framework of the MICS-Asia and HTAP. Atmos. Chem. Phys. 2017;17:935-963.

21. Li K, Liao H, Zhu J, Moch JM. Implications of RCP Emissions on Future $\mathrm{PM}_{2.5}$ Air Quality and Direct Radiative Forcing over China. J. Geophys. Res. 2016;121:12985-13008.

22. Wang S, Zhao Y, Chen G, Wang F, Aunan K, Hao J. Assessment of Population Exposure to Particulate Matter Pollution in Chongqing, China. Environ. Pollut. 2008;153:247-256.

23. Shakor ASB, Pahrol MA, Mazeli MI. Effects of Population Weighting on $\mathrm{PM}_{10}$ Concentration Estimation. J. Environ. Public Health. 2020;2020:1561823.

24. NAAQS National Ambient Air Quality Status \& Trends in India-2010. P R Division, Central Pollution Control Board; 2012. p.17-20.

25. van Donkelaar A, Martin RV, Brauer M, et al. Global Annual $\mathrm{PM}_{2.5}$ Grids from MODIS, MISR and SeaWiFS Aerosol Optical Depth (AOD) with GWR, 1998-2016. Palisades, NY: NASA Socioeconomic Data and Applications Center (SEDAC). https://doi.org/10.7927/H4ZK5DQS. [cited 8 January 2021].

26. Pope CA, Burnett RT, Thun MJ, et al. Lung Cancer, Cardiopulmonary Mortality, and Long-Term Exposure to Fine Particulate Air Pollution. JAMA 2002;287:1132-1141.

27. Rich DQ, Kipen HM, Zhang J, Kamat L, Wilson AC, Kostis JB. Triggering of Transmural Infarctions, but Not Nontransmural Infarctions, by Ambient Fine Particles. Environ. Health Perspect. 2010;118:1229-1234.

28. Wellenius GA, Burger MR, Coull BA, et al. Ambient Air Pollution and the Risk of Acute Ischemic Stroke. Arch. Intern. Med. 2013;172:229-234.

29. Anenberg, SC, West JJ, Horowitz LW, Tong DQ. The Global Burden of Air Pollution on Mortality: Anenberg et al. Respond. Environ. Health Perspect. 2010;118:A424-A425.

30. Burnett RT, Pope CA, Ezzati M, et al. An Integrated Risk Function for Estimating the Global Burden of Disease Attributable to Ambient Fine Particulate Matter Exposure. Environ. Health Perspect. 2014;122:397-403.

31. Lim SS, Vos T, Flaxman AD, et al. A Comparative Risk Assessment of Burden of Disease and Injury Attributable to 67 Risk Factors and Risk Factor Clusters in 21 Regions, 19902010: A Systematic Analysis for the Global Burden of Disease Study 2010. Lancet 2012;380:2224-2260.

32. Chowdhury S, Dey S. Cause-Specific Premature Death from Ambient $\mathrm{PM}_{2.5}$ Exposure in India: Estimate Adjusted for Baseline Mortality. J. Environ. Int.. 2016;91:283-290.

33. Census Info India 2011. Dashboards, Data Query, Houselisting and Housing Data, Population and Education [cited 8 January 2021]. Available from: http://www.dataforall.org/dashboard/ censusinfo/.

34. Venkataraman C, Brauer M, Tibrewal K, et al. Source Influence on Emission Pathways and Ambient PM 2.5 Pollution over India (2015-2050). Atmos. Chem. Phys. 2018;18:8017-8039.

35. Cohen AJ, Brauer M, Burnett R, et al. Estimates and 25-Year Trends of the Global Burden of Disease Attributable to Ambient Air Pollution: An Analysis of Data from the Global Burden of Diseases Study 2015. Lancet 2017;389:1907-1918.

36. World Health Organization WHO Air Quality Guidelines for Particulate Matter, Ozone, Nitrogen Dioxide and Sulfur Dioxide. Global Update 2005- Summary of Risk Assessment. 2006. p. 9-10.

37. Conibear L, Butt EW, Knote C, Arnold SR, Spracklen DV. Stringent Emission Control Policies Can Provide Large Improvements in Air Quality and Public Health in India. GeoHealth 2018;2:196-211.

38. Tiwari S, Srivastava AK, Bisht DS, Parmita P, Srivastava MK, Attri SD. Diurnal and Seasonal Variations of Black Carbon and $\mathrm{PM}_{2.5}$ over New Delhi, India: Influence of Meteorology. J. Atmos. Res. 2013;125-126:50-62.

39. Apte JS, Marshall JD, Cohen AJ, Brauer M. Addressing Global Mortality from Ambient $\mathrm{PM}_{2.5}$. J. Environ. Sci. Tech. 2015;49:8057-8066

40. Rural Development Department. Block Panchayats [cited 04 April 2021]. Available from: http://rdd.kerala.gov.in/index.php/2016-07-19-10-37-24/block-panchayaths.

41. Jal Jeevan Mission, Department of Drinking water and Sanitation, Ministry of Jal Shakti. Rural population [cited 04 April 2021]. Available from: https://ejalshakti.gov.in/IMISR eports/Reports/BasicInformation/rpt_RWS_RuralPopulation_B .aspx?Rep $=0$

42. Chowdhury S, Dey S, Guttikunda S, Pillarisetti A, Smith KR, Girolamo LD. Tracking Ambient $\mathrm{PM}_{2.5}$ Build-up in Delhi National Capital Region during the Dry Season over 15 Years Using a High-Resolution $(1 \mathrm{~km})$ Satellite Aerosol Dataset. $J$. Atmos. Environ. 2019;204:142-150.

43. Rao AM, Madhu E, Gupta K. Impact of Odd Even Scheme on Transportation Systems in Delhi. Transp. Dev. Econ. 2017;3:4.

44. Kumar P, Gulia S, Harrison RM, Khare M. The Influence of Odd-Even Car Trial on Fine and Coarse Particles in Delhi. Environ. Pollut. 2017;225:20-30.

45. Jain S, Aggarwal P, Sharma P, Kumar P. Vehicular Exhaust Emissions under Current and Alternative Future Policy Measures for Megacity Delhi, India. J. Trans Health. 2016;3:404412.

46. Central Electricity Authority Standard Technical Specification For Retrofit Of Wet Limestone Based Flue Gas Desulphurisation (FGD) System In A Typical $2 * 500$ MW Thermal Power Plant. 2017:1-448.

47. Rana M, Mittal SK, Beig G, Rana P. The Impact of Crop Residue Burning (CRB) on the Diurnal and Seasonal Variability of the Ozone and PM Levels at a Semi-Urban Site in the North-Western Indo-Gangetic Plain. J. Earth Syst. Sci. 2019:128-166. 